\title{
Sistema de informaçoes municipais como apoio à tomada de decisões dos cidadãos
}

\author{
GáudoLuzChiusdi Doutor em Administração. Universidade Estadual do Centro Oeste (Unicentro/PR) - Brasil. \\ prof.claudio.unicentro@gmail.com \\ DerisAdidesRezende Doutor em Engenharia de Produção. Pontifícia Universidade Católica do Paraná (PUC/PR) - \\ Brasil. denis.rezende@pucpr.br
}

\begin{abstract}
RESUMO
Para uma boa gestão pública é necessário que os gestores municipais propiciem informações pontuais aos cidadãos, visando suprir suas diversas demandas. 0 objetivo é identificar como os cidadãos da cidade de Londrina - Paraná têm acesso às informações geradas pela gestão pública. A metodologia da pesquisa caracterizou-se como estudo exploratório e quantitativo mediante amostragem não probabilística por conveniência junto a 172 cidadãos, cuja coleta foi realizada pessoalmente. Como parte do levantamento teórico foram abordados temas sobre sistema de informação, modelos e conceitos e sistema de informação de marketing e sua importância. Os resultados auferidos mostram que apenas $63 \%$ dos respondentes têm 0 hábito de acessar o site/portal da prefeitura para obter algum tipo de informação. A conclusão do estudo reitera que entre os destaques nos resultados aparecem o uso dos serviços on-line para busca de documentação, com $56 \%$ de acesso, seguido de acesso às informações gerais da cidade e aos telefones e horários de funcionamento dos departamentos, ambos com $46,5 \%$. Por outro lado, informações com baixa utilização são assuntos so bre as ofertas de estágios, com $26 \%$, acompanhamento das contas públicas e acesso à sala do empreendedor, ambos com $29 \%$ de citação, o que sugere pouco interesse desse grupo pesquisado sobre 0 assunto.
\end{abstract}

Palavras-chave: Informações municipais. Cidadãos. Sistema de informação. Tomada de decisão.

\section{Municipal information systems as support for citizens decision-making}

\begin{abstract}
For good public management, it is necessary that municipal managers provide punctual information to citizens in order to meet their diverse demands. The objective of this research is to identify how citizens of Londrina, in the state of Paraná, have access to information generated by public management. The research methodology was characterized as an exploratory and quantitative study by non-probabilistic sampling for convenience with 172 citizens. Data collection was carried out in person. As part of the theoretical survey, topics were discussed about information system, models and concepts and marketing information system and its importance. The results show that only $63 \%$ of the respondents access the city hall website to obtain some kind of information. And the conclusion of the study reiterates that among the highlights in the results are the use of online services to search for documentation with $56 \%$ access, followed by access to obtain general information of the city, and the telephones and operating hours of the departments both with

$46,5 \%$. On the other hand, some information with low number of accesses are about internship offers, with $26 \%$ access, follow-up of public accounts, and access to the entrepreneur's site, both with $29 \%$ citation, which suggests little interest of the group researched in these subjects.
\end{abstract}

Keywords: Municipal information. Citizens. Information system. Decision-making. 


\section{INTRODUÇÃO}

Para uma sólida gestão pública, além de atender às necessidades dos cidadãos, é necessário que os gestores municipais propiciem informações pontuais aos munícipes para suprir suas diversas demandas quanto à necessidade de informações atualizadas.

Os desafios na tomada de decisão são muitos, pois ocorrem devido à falta de informação e comunicação; conforme Porter (1999) e O'Brien (2004), apesar das informações estarem disponíveis, não há plena utilização, o que muitas vezes estão configurados com as respostas prontas, respostas estas que nem sempre correspondem às necessidades reais dos cidadãos.

Um dos primeiros benefícios que um cidadão pode obter por meio do uso de tecnologia de informação baseada no sistema de informação são melhorias no sistema de comunicação, cujo processamento de informação torna-se mais rápido e ágil na gestão da empresa que é capaz de relacionar informações pertinentes a partir de diferentes fontes de dentro da organização (GOUNARIS; PANIGYRAKIS; CHATZIPANAGIOTOU, 2007).

Para terem acesso aos dados e informações, existe a necessidade de um sistema com uma solução que ofereça as informações de forma mais rápida e de fácil acesso, o que muitas vezes é de desconhecimento de muitos cidadãos (CHIUSOLI; STEFANO, 2016; SOUALHIA; MEJ BRI, 2014). Nesse caso, a proposta de programa para uma cidade digital estratégica é muito propícia, pois além de abastecer de informações os cidadãos comuns, auxiliaria os atores locais, sejam eles profissionais liberais, empresários, estudantes, donas de casa, aposentados, servidores municipais em busca de dados, para assim consolidar as informações e tomar as decisões de forma rápida, no caso em especial, detalhes de sua cidade e município (REZENDE, 2012).

Como resultado, a indicação de um sistema de informação torna-se uma ferramenta fundamental para facilitar o progresso das organizações quando o gestor, enquanto cidadão, precisa tomar decisões diárias (KUBIAK; KOWALIK, 2010).

Para isso seria bem adequada uma estrutura de sistema de informações voltada às decisões do dia a dia, fundamental para a gestão dos cidadãos dentro do ambiente em que se encontram, seja para sua vida diária, nos estudos e, em especial, nas organizações, onde, certamente, o sistema contribuirá com subsídios para as decisões e o desenvolvimento da competitividade das mesmas (CHIUSOLI; IKEDA, 2010; MITCHELL; VOLKING, 1993).

Essas informações, no caso para as organizações, permitem auxiliar o ambiente mercadológico, até porque, pela pressão da competição, as decisões precisam se apoiar em ferramentas que consigam transformar os dados obtidos em informações aplicáveis, para isso há a necessidade dos gestores públicos cumprirem sua função de organizar os dados municipais de modo abrangente (WIERENGA; OUDE OPHUIS, 1997).

Como o gestor privado muitas vezes tem carências de informações pontuais, recorre a fontes secundárias publicadas pela administração pública, cujas informações tornam-se um elo desafiador para os gestores públicos aproveitarem as novas possibilidades proporcionadas pelos avanços das tecnologias da informação e comunicação (TICS), pois é imprescindível que os mesmos disponham de informações gerenciais e estratégicas adequadas, precisas e em tempo ágil, oportunas e customizadas para os cidadãos (LEITE; REZENDE, 2010). Assim, o Estado brasileiro, em todos os níveis, vem criando mecanismos para tirar proveito das TICS (SIMÃO, 2010). Um bom sistema de informações é fundamental para a obtenção de dados relevantes para a tomada de decisão em marketing - quanto mais correta e relevante a informação, maior a probabilidade de acerto (SALVADOR; IKEDA, 2018).

A partir desse cenário, a busca dessas informações que estão disponíveis fora do ambiente das organizações são auxiliadas pelas tecnologias da informação e comunicação, que nas últimas décadas têm apresentado evoluções e assim auxiliado as entidades governamentais a se modernizarem para não ficarem à margem do desenvolvimento da nova economia, o que dá indícios de uma cidade no caminho digital (SIMÃO, 2010; SALA, 2018).

Outro ponto de destaque é a garantia do acesso facilitado às informações públicas como forma de atender a pressão exercida pelo cidadão e, consequentemente, 0 aumento da transparência que é de grande 
importância para o exercício da cidadania. Dessa forma, uma maior transparência permite o controle social mais eficaz sobre os atos dos agentes públicos (ROSA et al., 2016).

A exemplo disso, encontra-se disponível uma ampla base de dados públicos secundários na esfera federal, estadual e municipal, em especial, como exemplo, a base de dados do IBGE (Instituto Brasileiro de Geografia e Estatística). Além de evitar um fluxo de trabalho baseado em documentos impressos em papel, visto que não só pode otimizar os processos internos de gestão, mas melhorar a eficiência do trabalho, pode ser usado para monitorar e supervisionar o trabalho dos funcionários (DONG, 2014).

Considerando o exposto, o problema de pesquisa é descobrir o envolvimento quanto ao uso e compreensão das informações disponíveis na esfera municipal, como apoio informacional ao cidadão local para tomar decisões, seja em situação de implantação de uma empresa na cidade, expansão dos negócios, em estudos acadêmicos, orientação ao cidadão sobre dados da cidade, da gestão pública e outras atividades diversas. Assim, questiona-se:

Quais são as informações mais habituais utilizadas pelos cidadãos? Até que ponto os cidadãos têm conhecimento das informações geradas pelas prefeituras e órgãos municipais? Há ciência dos programas de planejamento de governo enquanto gestão pública?

A justificativa da pesquisa se destaca pela necessidade de realçar o quanto os cidadãos abo rdados se sentem familiarizados e habituados a procurar informações nas suas cidades de origem ou cidades onde trabalham.

Conquanto a relevância da pesquisa ainda tem como destaque outro motivo importante, ao mesmo tempo em que se percebe a disponibilidade das informações em suas bases de dados fornecidas pela administração municipal, resta saber como os órgãos públicos podem melhorar a divulgação de sua plataforma de acesso às informações à população, a fim de se tornar uma cidade digital e inteligente simultaneamente, ao considerar suas diferenças conceituais e práticas (CHOURABI et al., 2012). Pois, diferentemente do conceito de cidade digital convencional e de cidade inteligente, a cidade digital estratégica é compreendida como a utilização dos recursos da tecnologia da informação na gestão municipal e na disponibilização de informações e serviços aos cidadãos, tratando-se de um projeto mais abrangente que apenas oferece internet aos cidadãos por meio de recursos convencionais de telecomunicações (REZENDE, 2012).

Diante do exposto, o objetivo do estudo é identificar como os cidadãos da cidade de Londrina, estado do Paraná, têm acesso às informações disponibilizadas pela gestão pública. E como objetivos específicos destacam-se as demais propostas norteadoras: i) verificar qual a principal forma de acesso à internet e de acesso ao e-mail; ii) levantar o índice de uso das informações municipais; iii) identificar quais as principais áreas de acesso às informações municipais.

\section{FUNDAMENTAÇÃO TEÓRICA}

$\mathrm{Na}$ fundamentação teórica, o estudo aborda alguns temas recorrentes ao assunto abordado, e Rezende (2012) destaca que os componentes da cidade digital estratégica são: i) a estratégia da cidade; ii) a informação para a tomada de decisão; iii) os serviços públicos oferecidos aos munícipes; e iv) os recursos de tecnologia da informação disponíveis na cidade.

Dessa forma, para melhor compreensão do assunto, registra-se que na abordagem a respeito da informação para tomada de decisão, torna-se como foco principal orientados mediante conceitos sobre sistema de informação (modelos e conceitos) e sistema de informação de marketing e sua importância.

\subsection{Sistema de informação: modelos e conceitos}

Os conceitos de sistema de informação e sua importância para a tomada de decisão são apresentados nessa seção. Mediante a concepção de estrutura de sistema de marketing, surgem as mais variadas interpretações de sistema de informação de marketing a partir do momento que novos modelos foram sendo elaborados e disponibilizados na literatura. Umas das definições mais clássicas verifica-se com Cox e Good 
(1967), que definem o sistema de informação de marketing como um campo de procedimentos e métodos formais de um plano de coleta de dados, análise e apresentação das informações para tomada de decisões de marketing.

A informação é algo muito valioso nos dias de hoje e, sobretudo, quando é necessário to mar decisões de qualquer natureza. Pensando nos cidadãos que incorporam o papel de trabalhador, estudante, empresário ou qualquer outro tipo de ator social quando necessita de informações de sua cidade, a primeira atitude é buscá-la na administração pública, por meio das suas bases de dados secundários. Pensando assim, de modo mais conceitual do ponto de vista mercadológico, existem alguns modelos de sistema de informação para auxílio na tomada de decisão, cuja Figura 1 demonstra o escopo de um sistema de informação voltado às decisões de mercado apoiado na tríade - sistema, informação e marketing, pensando em atividades voltadas a negócios. Werner (1982):

Este tripé, i) Sistema; ii) Informação e iii) Marketing é analisado da seguinte forma, segundo Mayros e

i) sistema: é toda estrutura conjunta, unificando e usando os dados brutos, informações, relatórios e modelos estatísticos que vão ao encontro dos objetivos propostos. 0 sistema é processado por meio de dados brutos extraídos de diversas fontes, sejam primária ou secundária. São analisados por meio de relatórios ou modelos estatísticos que se transformam em informações que auxiliam nas tomadas de decisões.

ii) informação: ela se distingue de dados, pois são números brutos, então a informação é o processamento desses dados, transformados em informação, importante para tomada das decisões.

iii) marketing: o gestor, no caso o cidadão, diariamente se encontra diante de problemas e questões que requerem do mesmo tomadas de decisões sobre os indicadores de sua cidade, por exemplo, dados demográficos, arrecadação, número de empresas etc.

Assim, o servidor público na qualidade de cidadão, como gestor de uma organização, por exemplo, pode confiar na sua intuição para se apoiar na tomada de decisão, ou de modo mais seguro, estudar as informações que darão respostas as suas indagações e resolverão seus problemas diários por meio dos dados secundários ofertad os pela administração municipal. Sabe-se que a tomada de decisões sempre envolve risco, uma vez que se trata de avaliação de receitas, custos, resultados e eventos futuros, nenhum dos quais pode ser conhecido, e a informação reduz a incerteza e ajuda o gestor a ver os efeitos prováveis das decisões, cumprindo assim a função do sistema de informação de marketing (ISMAIL, 2011). 
Figura 1 - 0 sistema de informação de marketing: uma definição

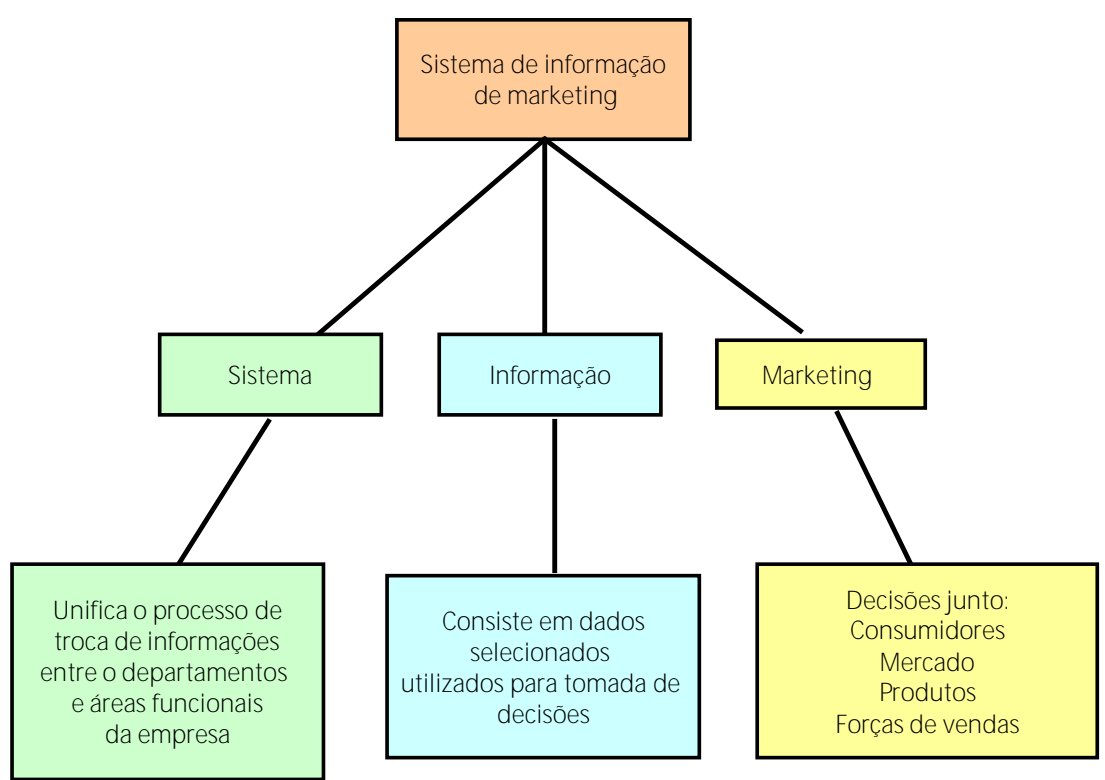

Fonte: Mayros e Werner (1982, p. 366).

Entre vários modelos encontrados na literatura, destaca-se um modelo que é de autoria de Chiusoli e Ikeda (2010), idealizado a partir de uma tese de doutorado que se pautou em mais de 30 modelos analisados. A sua síntese propõe o entendimento com base na descrição a seguir e nas etapas propostas (Figura 2):

i) fontes de dados: provenientes do ambiente de marketing externo, macro e microambiente e do ambiente interno.

ii) subsistema de entrada: informações originadas a partir dos dados internos da empresa (fontes secundárias), pesquisa de marketing e inteligência competitiva (fontes primárias).

iii) processamento de dados: tecnologia de informação apta a gerenciar e dar apoio à tomada de decisões de mercado, onde associa-se aos softwares disponíveis e que faz o processamento das informações. Cabe destacar que a evolução da tecnologia de informação (TI) permitiu gerar relatórios diversos, e ainda mais, o advento do sistema de informação geográfica (SIG) propiciou gerar dados com informações em formatos de mapas digitais por meio de uma visão espacial.

iv) decisões de marketing: se divide em uma estrutura de marketing para um melhor planejamento, segmentação e posicionamento dos produtos e serviços. Sendo que o subsistema de saídas é por meio da estrutura corporativa, que permite dar condições ao gestor das organizações em articular decisões estratégicas para a composição de seus produtos e serviços, a qual preço atuar, ações de canal de distribuição e estratégia de comunicação como forma de tomada de decisão dessas atividades.

v) tomador de decisão: é o responsável pela decisão final, no caso, é o cidadão comum. 
Figura 2 - Sistema de informação de marketing como atividade estratégica

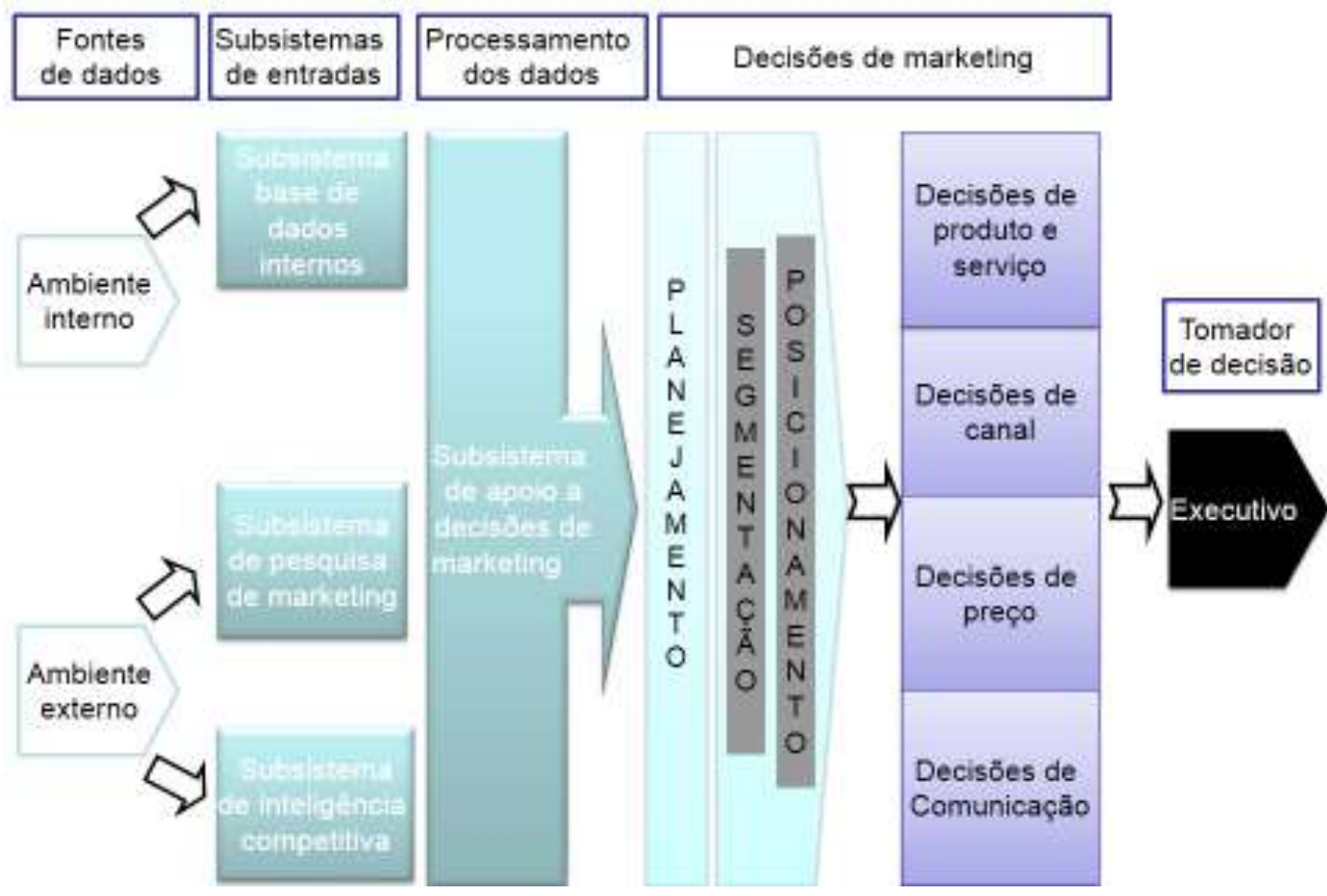

Fonte: Chiusoli e lkeda (2010)

No modelo de um sistema de informação aplicado para gestão da tomada de decisões de marketing, Chiusoli e Ikeda (2010) afirmam que os dados internos de uma organização dependem somente da mesma; por outro lado, os dados secundários, quando se necessita acessar essas fontes junto à administração pública, espera-se que tenham validade, sejam de fácil acesso e de forma organizada.

Destaca-se, dessa forma, que um modelo de sistema de informação de marketing (SIM) é composto por pessoas, equipamentos e procedimentos para a coleta, classificação, análise, avaliação e distribuição de informações necessárias de maneira precisa e oportuna para os que necessitam tomar decisões (CHIUSOLI; IKEDA, 2010; O'BRIEN; SCHOENBACHLER; GORDON, 1995).

Torna-se assim uma ferramenta que apoia os gerentes no processo decisório de marketing, provendo ligações integradas entre departamentos funcionais ou divisões e minimizando os desafios devido a competição global, a qual exige da organização uma quantidade grande de dados para a tomada de decisão oportuna e efetiva, endossado com o uso de sistemas computadorizados (BERHAN; KITAW, 2012).

Os dados internos da empresa são considerados como valiosas informações para as decisões estratégicas, por isto a grande importância de coletá-los da forma mais completa possível.

As empresas, de modo geral, têm muitas informações, porém, torna-se muito comum manter um pequeno banco de dados, no qual conste o cadastro de cliente, controle de compras, contas a receber e a pagar com softwares customizados, e até gratuitos, disponíveis na internet, no entanto, com bastante dificuldade em encontrar adequadamente dados comportamentais do consumidor e perfil socioeconômico (CHIUSOLI; IKEDA, 2010; PESZKO; 2015).

Hoje, extrair as informações do banco de dados dentro das organizações parece ser um trabalho muito dispendioso de tempo e conhecimento técnico avançado, porém se os cidadãos que representam essas empresas tivessem acesso a modestos relatórios, mesmo para as pequenas organizações, já seria um grande avanço, e sua análise auxiliaria muito na tomada de decisão para uma melhor estratégia como posicionamento competitivo (O'BRIEN, 2004).

Apesar do conceito, faltam aplicações práticas, como aplicação de pesquisa e prospecção de novos clientes, traçar metas e estratégias de mercado sem precisar recorrer apenas aos dados dos sistemas 
informatizados, que estão configurados com as respostas prontas, respostas estas que nem sempre correspondem as suas necessidades, de acordo com o estudo de Porter (1999).

Neste contexto, surge então a necessidade de uma análise minuciosa e cruzamento de informações, dados que já estão contidos na empresa e são poucos utilizados. Este levantamento deve primeiramente ser feito verificando seus clientes, parceiros, fornecedores, colaboradores, entre outros; cujas informações consistem em trabalhar de forma simultânea, integrando a informação de forma mais fácil, com menor custo, menor tempo e retrabalho de informação (CHIUSOLI; IKEDA, 2010).

Assim, ao introduzir um sistema de informação de marketing, deve ser precedido pela descrição dos processos internos de negócio da organização e detalhamento com base em parâmetros quantitativos para avaliação (NOVIKOVA, 2015).

Conquanto, dessa forma, os sistemas de informação como estratégia disponibilizam informações agrupadas e macro relacionadas com o meio ambiente interno e externo à organização (REZENDE; PEREIRA, 2013). E quanto mais confiáveis, adequadas e ágeis forem as informações produzidas pelas estruturas de controle, mais seguras serão as decisões tomadas no futuro (CASTRO, 2008).

Em consequência disso, em todos os âmbitos da administração pública os sistemas de informação são essenciais, que garantem agilidade, confiabilidade e qualidade de informações. Nesse ínterim, são criados softwares para auxiliar a tomada de decisão e levantamento de informações como forma de implementação das políticas públicas (MOTA; OLIVEIRA JUNIOR; FREITAS, 2016)

\subsection{Sistema de informação de marketing: importância}

Para se ter uma ideia da importância da informação obtida por meio de dados secundários, estudos aplicados em 2005 e em 2012 junto a gestores de algumas organizações sugerem que a procura por base de dados secundários, em 2005, correspondia a 71\%, subindo para 85\% em 2012; como de grande importância e ao serem inquiridos quanto ao efetivo grau de utilização, o índice vai de 63\% (2005) para 80\% (2012). Muito provavelmente, considera-se como uso dos dados secundários disponíveis as informações obtidas por meio dos agentes públicos, seja na esfera municipal, estadual e federal (CHIUSOLI; IKEDA, 2010; CHIUSOLI; STEFANO, 2016).

Estudos revelam que as empresas dependem muito dos dados da contabilidade como fonte interna de informações, especialmente dados e relatórios de vendas, confiando mais nos contatos pessoais em contato direto com clientes e representantes de vendas, que constituem uma fonte de informação segura, do que em fontes econômicas e governamentais (RAYMOND; BRISOUX; AZAMI, 2001).

A partir dessa análise, constata-se que a informação pode ser algo tangível ou não, porém ambas têm valor comercial e valor estratégico. Toda informação, seja ela coletada internamente por meio de recursos como máquinas, softwares, relatórios e demonstrativos contábeis, integram um subsistema de entrada. Em um ambiente crescentemente complexo e turbulento, o uso da tecnologia de informação se tornou um fator de sucesso crítico para organizações (RAYMOND; BRISOUX. AZAMI, 2001).

$O$ conceito de sistema destaca-se pelo conjunto de partes que interagem entre si, integrando-se para atingir um objetivo, e na informática é o conjunto de software, hardware e recursos humanos, componentes da $\mathrm{Tl}$ e seus recursos integrados que transformam dados em informações para geração de conhecimento (REZENDE, 2012). Desta forma, níveis de digitalização para uma cidade digital são fortemente influenciados pelo sistema de informação (PATASIENE, PATASIUS; 2014).

Assim, os recursos da tecnologia de informação e comunicação são usados intensivamente na economia e nas organizações e, também, para dar suporte aos cidadãos, uma vez que surgiram as redes comunitárias como extensões de domínio público dentro do espaço cibernético, através das quais é possível obter diversas informações na atualidade (BESSELAAR; BECKERS, 2005).

A tecnologia, em termos de sua capacidade de gerar informação por meio de aplicativos de tecnologia da informação, é fundamental para o sucesso de uma organização, dessa forma, um bom sistema de informações de marketing equilibra as informações que os cidadãos gostariam de ter e o que realmente necessitam (ISMAIL, 2011). 
Em destaque à importância da informação, Murugadas (2015) sugere que para uma boa gestão de informação, a administração pública deve ter algumas infraestruturas básicas, como pontos de acesso wi-fi espalhados pela cidade, com rápida conexão de banda larga para acesso a indicadores educacionais, publicações diversas, dados da população, número de empresas, dados do mercado de trabalho, indicadores da saúde, de lazer e outros.

Desse modo, gerar informações, por parte dos gestores públicos, tornou-se um protótipo para as cidades avançarem no estágio de uma sociedade do conhecimento, em que a tecnologia de informação e comunicação permite fornecer acesso ao conhecimento explícito ao cidadão, caracterizando assim uma boa gestão e serviços públicos mediante funcionários bem treinados, cuja vontade política são aspectos cruciais para o desenvolvimento local (STOCK, 2011).

\section{METODOLOGIA DA PESQUISA}

Como método de pesquisa, realizou-se um estudo exploratório mediante revisão da literatura em artigos nacionais e, principalmente, internacionais, sendo que o principal destaque foi em descobertas de ideias e intuições, cujo objetivo foi familiarizar-se e conseguir nova compreensão sobre o assunto para poder formular um problema de pesquisa mais adequado e criar os testes de hipóteses (GIL, 2008; MARCONI; LAKATOS, 2010; CERVO; BERVIAN e SILVA, 2007). Ainda houve uma survey, mediante a coleta de dados, de cunho descritivo, que preten deu descrever comportamentos, hábitos e atitudes dos cidadãos relacionados ao tema estudado (ROESCH, 2005; SIEGEL; CASTELLAN, 2006; FREITAS et al., 2000).

Quanto à técnica de pesquisa foi utilizada a quantitativa, quanto a natureza das variáveis; que procurou quantificar os dados e aplicar alguma forma da análise estatística à pesquisa; quanto ao tempo, foi compreendido por um corte transversal, uma vez que a coleta dos dados ocorreu somente uma única vez, pretendendo descrever e analisar o estado das variáveis em um dado momento (FREITAS et al.,2000).

Quanto ao processo de amostragem, foi considerado como não probabilístico por conveniência junto a 172 cidadãos, que relataram seus sentimentos, atitudes e percepções das atividades do governo local; e a unidade de observação teve como foco principal o empresário, profissional liberal, autônomo, executivos, professor e servidor público em uma cidade do estado do Paraná, como estudo piloto.

o questionário foi estruturado em duas formas, utilizando-se da tecnologia do Google Forms, e um segundo questionário para coleta dos dados por meio de entrevistas pessoais, cujo período da coleta compreendeu 0 ano de 2017. 0 modelo que instrumentalizou a coleta de dados modelado, cujo teor consta com 14 variáveis, utilizou-se de escala ordinal, mediante pré-testes para uma melhor configuração de validade e confiabilidade, cujo objetivo é refinar, visando garantir que ele realmente vai medir aquilo a que se propõe (FREITAS et al., 2000; MARTINS, 2006).

Elaborada e aplicada a coleta de dados, tem-se o seguinte perfil de entrevistados: i) predominância dos homens ( $70 \%)$, contra $30 \%$ da participação das mulheres; ii) maior concentração de entrevistados entre 31 a 50 anos (quase 60\%) e; iii) 9 a cada 10 respondentes (90\%) têm acesso e usa a rede social. Para as análises mediante cruzamentos de dados e teste de hipótese houve um agrupamento entre as variáveis gênero e faixa etária na seguinte configuração: gênero até 40 anos e acima de 40 anos.

Após a obtenção dos dados coletados, os mesmos foram armazenados e processados eletronicamente no programa SPSS (v.22). A análise dos dados consistiu em análises univariadas e bivariadas com base em frequências absolutas e relativas. As medidas de associação foram testadas por meio do teste não paramétrico, o Qui-Quadrado e o teste de correlação de Spearman (SIEGEL; CASTELLAN, 2006). Para o teste de correlação de Spearman, valendo-se que o $\mathrm{p}$ (positivo ou negativo) pode variar entre correlação bem fraca (até 0,19$)$, correlação fraca $(0,20$ a 0,39$)$, correlação moderada $(0,40$ a 0,69$)$, correlação forte $(0,70$ a 0,89$)$ e correlação muito forte $(0,90$ a 1$)$ para medir a intensidade da relação entre variáveis ordinais. Todos os resultados das análises bivariadas foram avaliados com nível de significância estatística de $5 \%(p<0,05)$. Vale destacar que para aplicação dos testes (qui-quadrado e correlação de Spearman) as escalas concordo/discordo tiveram alguns ajustes quanto ao agrupamento para dar força a aplicação do teste estatístico. 
A partir disso, elaborou-se o protocolo de pesquisa, para atender aos objetivos e à questão-problema, considerando seus constructos em relação à fundamentação teórica, às variáveis e às questões correspondentes, suas escalas e técnicas de coletas. Além do perfil dos entrevistados, têm-se os constructos (14 variáveis) sobre sistema de informação, entre os quais se destaca os assuntos: secretarias de governo; órgãos públicos; serviços on-line; fone e horários; portal da transparência; contas públicas; licitações e editais públicos; concursos e testes seletivos; estágios; núcleo de comunicação; sala do empreendedor; sistema eletrônico de informações e nota fiscal eletrônica. A partir dessa exposição, postula-se as hipóteses da pesquisa a partir dos conceitos so bre sistema de informação municipal e sistema de informação de marketing (Quadro 1).

\section{Quadro 1 - Testes de hipóteses}

Teste não paramétrico $\quad \mathrm{H1}$ : Não há diferença significativa quanto ao uso de sistema de informação qui-quadrado municipal pelos cidadãos, considerando as variáveis: gênero e faixa etária.

Teste não paramétrico, $\quad \mathrm{H} 2$ : Não há forte correlação positiva entre as variáveis pesquisadas

correlação de Spearman

Fonte: elaborado pelo Autor (2017)

\section{RESULTADOS E DISCUSSÃO}

Na sequência, apresenta-se os resultados e sua análise mediante uso das estatísticas descritivas em relação ao perfil e hábitos quanto ao uso da internet. Após, relata-se os resultados por meio dos testes não paramétricos: qui-quadrado e correlação de Spearman.

\subsection{Análise da estatística descritiva: perfil e hábitos de uso da internet}

Acima de $90 \%$ têm acesso e usam a rede social, e um dado interessante é que a forma de acesso à internet é mais utilizada por meio de aplicativos no celular (37\%) e acesso aos e-mailspor computador (37\%). Tanto homens como mulheres abaixo de 40 anos utilizam mais celulares para acessar a internet, para ver os $e$ mails, por exemplo (Quadro 2).

Quadro 2 - Estatística descritiva sobre o uso e acesso às informações

\begin{tabular}{|c|c|c|c|c|c|}
\hline Sexo & Feminino & Masculino & Total & & \\
\hline & $30,2 \%$ & $69,8 \%$ & $100,00 \%$ & & \\
\hline \multirow{2}{*}{ Faixa etária } & Até 30 anos & $\operatorname{De} 31 / 40$ & De 41/50 & $50+$ & Total \\
\hline & $10,5 \%$ & $30,8 \%$ & $26,2 \%$ & $32,6 \%$ & $100,00 \%$ \\
\hline \multirow[t]{2}{*}{ Faixa etária / Sexo } & Feminino/40 & Feminino/40+ & Masculino/40 & Masculino/40+ & Total \\
\hline & $12,2 \%$ & $18,0 \%$ & $29,1 \%$ & $40,7 \%$ & $100,00 \%$ \\
\hline \multirow[t]{2}{*}{$\begin{array}{c}\text { Forma de acesso à } \\
\text { internet }\end{array}$} & Celular/Tablet & Computador & Notebook & Total & \\
\hline & $37,2 \%$ & $34,3 \%$ & $28,5 \%$ & $100,00 \%$ & \\
\hline \multirow[t]{2}{*}{$\begin{array}{c}\text { Forma de acesso ao } \\
\text { e-mail }\end{array}$} & Celular/Tablet & Computador & Notebook & Total & \\
\hline & $34,9 \%$ & $37,2 \%$ & $27,9 \%$ & $100,00 \%$ & \\
\hline
\end{tabular}

Ao considerar o perfil do respondente no que diz a forma de acesso ao e-mail e à internet, há diferenças significativas mediante o teste não paramétrico qui-quadrado $(p<0,05)$, em que mostra a aderência com que os que usam computadores para acessar o e-mail, também o fazem para acessar a internet (78\%). Da mesma forma, quem acessa o e-mail por meio do notebook, acessa também a internet (77\%); e quem acessa pelo celular/tablet, o índice é de 75\%, conforme aponta o Quadro 3. 
Quadro 3 - Relação entre a forma de acesso à internet e ao e-mail

\begin{tabular}{|l|c|c|c|c|}
\hline & \multicolumn{3}{|c|}{ Acesso e-mail * } & Total \\
\hline \multicolumn{1}{|c|}{ Acesso à internet por } & Computador & Notebook & Celular/Tablet & $37,2 \%$ \\
\hline Celular/Tablet & $15,6 \%$ & $18,8 \%$ & $75,0 \%$ & $34,3 \%$ \\
\hline Computador & $78,1 \%$ & $4,2 \%$ & $11,7 \%$ & $28,5 \%$ \\
\hline Notebook & $6,3 \%$ & $77,1 \%$ & $13,3 \%$ & $100,0 \%$ \\
\hline
\end{tabular}

Fonte: pesquisa (2017) - *: significativo a $5 \%(p<0,05)$

Uma melhor visualização por meio de um mapa espacial utilizando a técnica estatística multivariada, a análise de correspondência pode ser evidenciada na Figura 3, que destaca a relação quanto a forma de acesso à internet e e-mail, considerando os meios de uso, seja computador, notebook e celular/ tablet. Esses dados sugerem que o cidadão tem um comportamento muito aderente quanto ao acesso em função dos recursos que possuem no momento. A exemplo disso, que utiliza mais o computador costuma acessar seus e-mails (78\%), da mesma forma que usa mais notebook, o índice de acesso aos e-mailsé de 77\% e quem gosta de usar o celular/ tablet índice é de $75 \%$.

Figura 3 - Análise de correspondência: forma de acesso à internet e ao e-mail

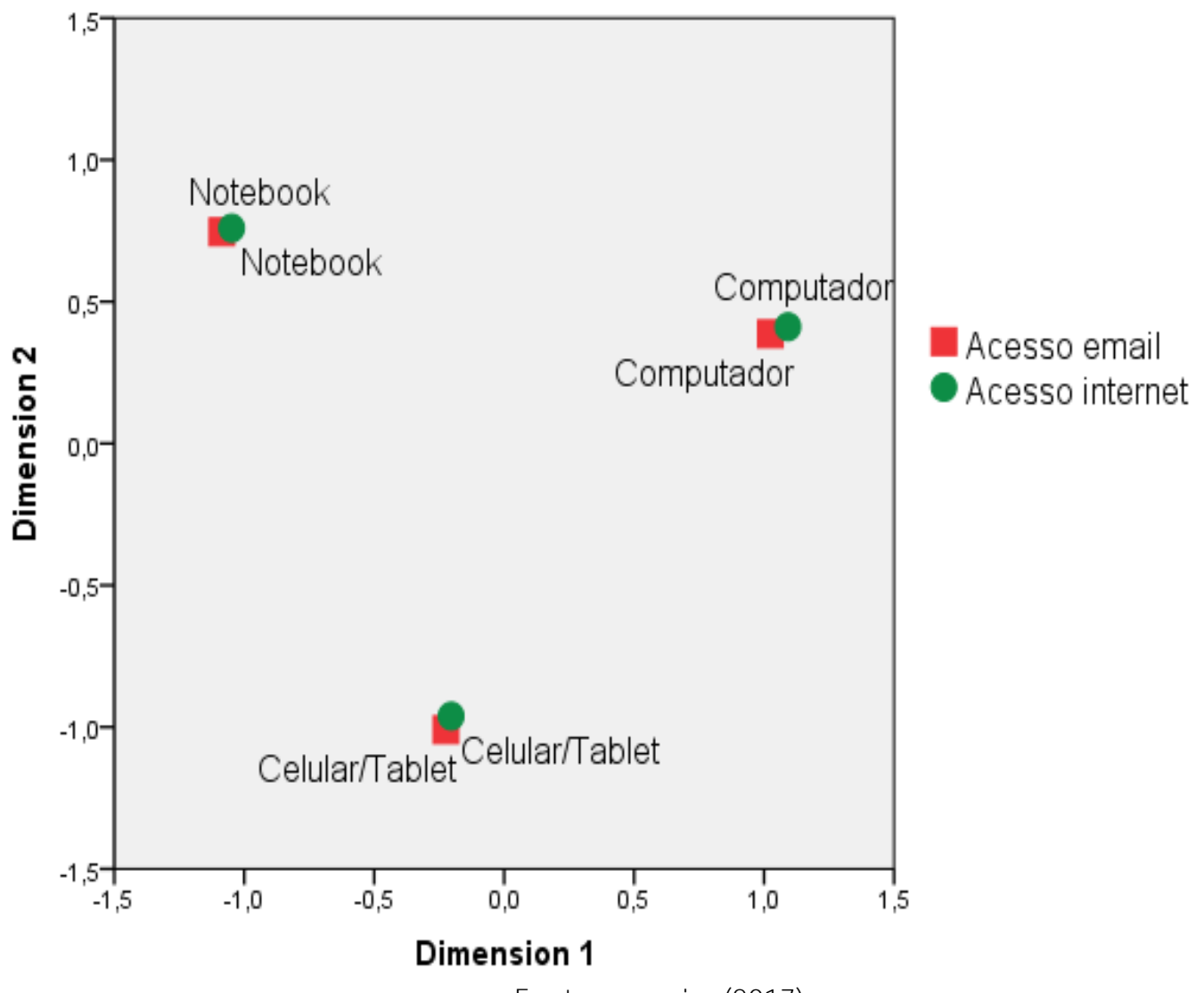

Fonte: pesquisa (2017)

\subsection{Análise do teste não paramétrico: qui-quadrado}

Ao navegar pelo site/portal da prefeitura é possível encontrar muitas informações, dentre as quais são destaques no estudo as variáveis de 1 a 14, seguem alguns elementos adicionais: 
A variável 1 explora assuntos referentes às secretarias de governo, que engloba 16 pastas: agricultura e abastecimento; ambiente; assistência social; cultura; defesa social; educação; fazenda; gestão pública; governo; idoso; políticas para as mulheres; obras e pavimentação; planejamento, orçamento e tecnologia; recursos humanos; saúde e trabalho, emprego e renda.

A variável 2 refere-se aos órgãos públicos, que é composto entre as principais: administração dos cemitérios e serviços funerários; agência de trânsito, companhia de habitação; companhia de desenvolvimento; companhia de planejamento e Procon.

A variável 3 refere-se ao acesso aos serviços on-line de documentação para: alvará de licenças, certidão negativa; certidão narrativa; IPTU; ITBI; ISS; licença sanitária; obras; protocolo on-line; guia de serviços; subvenção social; fale com a prefeitura; comprovante de rendimentos pagos de retenção IR.

A variável 4 refere-se aos telefones e horários de funcionamento e expediente da prefeitura e secretarias.

A variável 5 trata da informação sobre 0 acesso ao portal da transparência da prefeitura, que é um ambiente criado para facilitar o acesso às informações pelo cidadão, tais como: as informações de contratos e convênios; finanças, licitações; pessoal; projetos e obras e orçamentos.

A variável 6 destaca as contas públicas, como: audiências públicas; balanço; execução orçamentária; lei de responsabilidade fiscal; LRF - relatórios resumidos; parecer prévio e versão simplificada.

A variável 7 refere-se às licitações e editais públicos disponíveis, com editais, chamamento público, cotação eletrônica e seleção pública.

A variável 8 aponta para os concursos e testes seletivos para preenchimento de vagas em diversas áreas, bolsistas e seleção de estagiários.

A variável 9 é assunto relativo à oferta de estágios, em que são ofertados os editais, descreve as instituições conveniadas, formulários e legislação para estágio.

A variável 10 aborda sobre o núcleo de comunicação, que contém arquivo de notícias; jornal oficial; fotojornalismo; logo da prefeitura; agendas culturais e esportivas.

A variável 11 refere-se à sala do empreendedor, que gera um link direto ao site da companhia de desenvolvimento, com várias informações importantes sobre projeto para o desenvolvimento econômico e social da cidade.

A variável 12 refere-se ao sistema eletrônico de informações (SEI) utilizado pela prefeitura do município para a tramitação de processos administrativos, documentos e informações.

A variável 13 destaca assunto relativo a informações gerais da cidade, como perfil da população, fotos, mapas etc.

A variável 14 trata sobre à emissão de nota fiscal eletrônica, utilizadas pelas empresas da cidade.

Dessa forma, o Quadro 4 apresenta as principais variáveis de acesso quanto ao uso e acesso às informações, uma vez que 6 entre 10 respondentes têm o hábito de acessar o site/portal da prefeitura para obter algum tipo de informação (63\%). Considerando esse resultado, gerar informações por parte dos gestores públicos tornou-se possível mediante o avanço da tecnologia de informação e comunicação, caracterizando assim uma boa gestão e serviços públicos, mediante funcionários bem treinados (STOCK, 2011).

Entre os destaques estão os serviços online de documentação para emissão de guias, certidões, alvarás etc. com quase $56 \%$ de acesso (var3), seguido de acesso às informações gerais da cidade, como perfil da população, fotos, mapas (var13), e aos telefones e horários de funcionamento dos departamentos (var4), ambos com $46,5 \%$. Na outra ponta, informações com baixo uso são assuntos a respeito de ofertas de estágios (var9), com $26 \%$ de citação, acompanhamento das contas públicas (var6) e acesso à sala do empreendedor (var11), ambos com $29 \%$ de citação, o que sugere pouco interesse desse grupo pesquisado por algum motivo que o estudo não explorou, limitando-se ao respondente indicar apenas as informações mais utilizadas. 
Quadro 4 - Estatística descritiva sobre o uso e acesso às informações (\%)

\begin{tabular}{|c|l|c|c|c|}
\hline & \multicolumn{1}{|c|}{ Uso e acesso às informações } & Acesso & $\begin{array}{c}\text { Não } \\
\text { acesso }\end{array}$ & Total \\
\hline Filtro & \multicolumn{1}{|c}{ Costuma acessar site/portal da prefeitura } & 62,8 & 37,2 & 100 \\
\hline Var1 & $\begin{array}{l}\text { Assunto relativo às SECRETARIAS DE GOVERNO, como esportes, } \\
\text { educação, saúde, RH etc. }\end{array}$ & 42,4 & 57,6 & 100 \\
\hline Var2 & Acesso às empresas públicas: AUTARQUIAS & 44,2 & 55,8 & 100 \\
\hline Var3 & $\begin{array}{l}\text { Acesso aos SERVIÇOS ON-LINE DE DOCUMENTAÇÃO para emissão } \\
\text { de guias, certidóes, alvarás etc. }\end{array}$ & 55,8 & 44,2 & 100 \\
\hline Var4 & Aos FONES e HORÁRIOS de funcionamento dos departamentos & 46,5 & 53,5 & 100 \\
\hline Var5 & $\begin{array}{l}\text { Acesso ao PORTAL DA TRANSPARÊNCIA que mostra as informações } \\
\text { de contratos, finanças, licitações do município etc. }\end{array}$ & 36,6 & 63,4 & 100 \\
\hline Var6 & $\begin{array}{l}\text { No acompanhamento das CONTAS PÚBLICAS (orçamentos, } \\
\text { balançOs, audiência etc.) }\end{array}$ & 29,1 & 70,9 & 100 \\
\hline Var7 & Nas LICITAÇÕES e EDITAIS PÚBLICOS disponíveis & 38,4 & 61,6 & 100 \\
\hline Var8 & Nos CONCURSOS e TESTES SELETIVOS disponíveis & 39,5 & 60,5 & 100 \\
\hline Var9 & Assunto relativo à oferta de ESTÁGIOS para estudantes & 73,2 & 100 \\
\hline Var10 & $\begin{array}{l}\text { No NÚCLEO DE COMUNICAÇÃO, que contém arquivo, notícias, } \\
\text { agendas e informativos da prefeitura }\end{array}$ & 36,6 & 63,4 & 100 \\
\hline Var11 & $\begin{array}{l}\text { Acesso à sala do EMPREENDEDOR, que disponibiliza linhas de } \\
\text { créditos às empresas }\end{array}$ & 29,1 & 70,9 & 100 \\
\hline Var12 & $\begin{array}{l}\text { Acesso ao SISTEMA ELETRÔNICO DE INFORMAÇÕES (SEI) para } \\
\text { verificar a tramitação de documentos, processos administrativos }\end{array}$ & 38,4 & 61,6 & 100 \\
\hline Var13 & $\begin{array}{l}\text { Assunto relativo às INFORMAÇÕES GERAIS DA CIDADE, como perfil } \\
\text { da população, fotos, mapas etc. }\end{array}$ & 46,5 & 53,5 & 100 \\
\hline Var14 & \begin{tabular}{l} 
Para emissão de NOTA FISCAL ELETRÔNICA \\
\hline
\end{tabular} & 41,3 & 58,7 & 100 \\
\hline
\end{tabular}
Fonte: pesquisa (2017)

Ainda com base nas informações do Quadro 5, mediante os cruzamentos das variáveis pelo perfil quanto ao gênero e faixa etária, alguns destaques podem ser vistos, uma vez que os serviços on-line de documentação para emissão de guias, certidões, alvarás etc. aparece quase com $56 \%$ de citação entre os respondentes (var3), destacando-se as mulheres, com $62 \%$, enquanto os homens aparecem com $53 \%$.

Já considerando a faixa etária, verifica-se que os mais jovens, entre 20 a 30 anos, acessam mais no portal/site da prefeitura os serviços on-line de documentação (var3) e aos fones e horários de funcionamento dos departamentos (var4), com $67 \%$ e $61 \%$ respectivamente. 0 mesmo ocorre entre os respondentes entre 31 a 40 anos, que na var12 são citados com quase $57 \%$, e na var 13 com $49 \%$. Já os entrevistados entre 41 a 50 anos e acima de 50 anos, apesar do item var13 (56\% e $52 \%$ respectivamente) ser o quesito mais citado, 0 assunto que trata sobre informações gerais da cidade (var22) é o segundo mais importante na acessibilidade, com $53 \%$ e $48 \%$ respectivamente.

Quadro 5 - Estatística descritiva vs sexo, faixa etária e sexo/faixa etária (\%)

\begin{tabular}{|c|c|c|c|c|c|c|c|c|c|c|c|}
\hline Bloco II & $\mathrm{M}$ & $\mathrm{F}$ & $20 / 30$ & $31 / 40$ & $41 / 50$ & $50+$ & $\mathrm{M} / 40$ & $\mathrm{M} / 40+$ & $\mathrm{F} / 40$ & $\mathrm{~F} / 40+$ & Total \\
\hline Filtro & 60,0 & 69,2 & 66,7 & 66,0 & 62,2 & 58,9 & 62,0 & 58,6 & 76,2 & 64,5 & 62,8 \\
\hline Var1 & 41,7 & 44,2 & 44,4 & 39,6 & 44,4 & 42,9 & 40,0 & 42,9 & 42,9 & 45,2 & 42,4 \\
\hline Var2 & 43,3 & 46,2 & 50,0 & 43,4 & 44,4 & 42,9 & 42,0 & 44,3 & 52,4 & 41,9 & 44,2 \\
\hline Var3 & 53,3 & 61,5 & 66,7 & 56,6 & 55,6 & 51,8 & 54,0 & 52,9 & 71,4 & 54,8 & 55,8 \\
\hline Var4 & 44,2 & 51,9 & 61,1 & 49,1 & 46,7 & 39,3 & 52,0 & 38,6 & 52,4 & 51,6 & 46,5 \\
\hline Var5 & 35,8 & 38,5 & 33,3 & 28,3 & 42,2 & 41,1 & 28,0 & 41,4 & 33,3 & 41,9 & 36,6 \\
\hline Var6 & 28,3 & 30,8 & 27,8 & 20,8 & 37,8 & 30,4 & 22,0 & 32,9 & 23,8 & 35,5 & 29,1 \\
\hline Var7 & 36,7 & 42,3 & 44,4 & 34,0 & 42,2 & 37,5 & 38,0 & 35,7 & 33,3 & 48,4 & 38,4 \\
\hline Var8 & 35,8 & 48,1 & 55,6 & 32,1 & 42,2 & 39,3 & 38,0 & 34,3 & 38,1 & 54,8 & 39,5 \\
\hline
\end{tabular}




\begin{tabular}{|c|c|c|c|c|c|c|c|c|c|c|c|}
\hline Var9 & 23,3 & 32,7 & 33,3 & 20,8 & 28,9 & 26,8 & 22,0 & 24,3 & 28,6 & 35,5 & 26,2 \\
\hline Var10 & 32,5 & 46,2 & 38,9 & 32,1 & 35,6 & 41,1 & 32,0 & 32,9 & 38,1 & 51,6 & 36,6 \\
\hline Var11 & 30,0 & 26,9 & 33,3 & 22,6 & 31,1 & 32,1 & 28,0 & 31,4 & 19,0 & 32,3 & 29,1 \\
\hline Var12 & 40,0 & 34,6 & 44,4 & 30,2 & 42,2 & 41,1 & 34,0 & 44,3 & 33,3 & 35,5 & 38,4 \\
\hline Var13 & 45,0 & 50,0 & 44,4 & 39,6 & 53,3 & 48,2 & 40,0 & 48,6 & 42,9 & 54,8 & 46,5 \\
\hline Var14 & 41,7 & 40,4 & 33,3 & 43,4 & 42,2 & 41,1 & 42,0 & 41,4 & 38,1 & 41,9 & 41,3 \\
\hline
\end{tabular}

Fonte: pesquisa (2017)

$\mathrm{Na}$ interpretação do teste de hipótese, ao aplicar o teste do qui-quadrado, verifica-se que as frequências observadas, em relação às frequências esperadas, apresentam o nível de significância estatística $(p<0,01$ e $p<0,05)$, quando há diferenças entre as frequências dos grupos pesquisados.

Aplicando-se o teste do qui-quadrado, verifica-se que as frequências observadas não são diferentes das frequências esperadas, desse modo, pode-se sugerir que não existe diferença entre as frequências (contagens) dos grupos. Em outros termos, não há associação entre os grupos referentes às variáveis pesquisadas quanto ao uso e acesso às informações ao verificar as respostas quanto ao gênero e faixa etária, bem como a combinação de faixas etárias com gênero (Quadro 6).

Assim, é exposto a partir do Quadro 6 a elaboração, de forma resumida, do nível de significância das 14 variáveis analisadas em relação as 3 categorias de cruzamento, conforme a seguir: i) sexo; ii) faixa etária; e iii) gênero versusfaixa etária.

Assim, aceita-se a hipótese ( $\mathrm{H} 1$ ), pois não há diferença significativa quanto ao uso de informações dos serviços públicos pelos cidadãos, isto é, não há evidência estatística significativa, considerando os grupos: gênero e faixa etária.

Destaca-se, dessa forma, que no entendimento do teste estatístico aplicado há evidências de que os cidadãos têm comportamentos semelhantes quanto a busca de informações em relação às variáveis pesquisadas. Muito embora, quanto ao uso da informação, destaca-se que há um razoável índice (em torno de $60 \%)$ de acesso ao site/portal da prefeitura; sugere-se que, para uma boa gestão de informação, a administração pública deve ter algumas infraestruturas básicas, como pontos de acesso wi-fi espalhados pela cidade, com rápida conexão de banda larga para acesso a indicadores gerais e informacionais da gestão pública (MURUGADAS, 2015), onde os níveis de digitalização para uma proposta de cidade digital são fortemente influenciados por um bom sistema de informação (PATASIENE, PATASIUS; 2014).

Quadro 6 - Teste não paramétrico: Qui-quadrado vs sexo, faixa etária e sexo/faixa etária

\begin{tabular}{|c|l|c|c|c|}
\hline \multicolumn{1}{|c|}{ Bloco II-Uso e acesso às informações } & Sexo & $\begin{array}{c}\text { Faixa } \\
\text { etária }\end{array}$ & $\begin{array}{c}\text { Sexo/Faixa } \\
\text { etária }\end{array}$ \\
\hline Filtro & \multicolumn{1}{|c|}{ Costuma acessar site/portal da prefeitura } & NS & NS & NS \\
\hline Var1 & $\begin{array}{l}\text { Assunto relativo às SECRETARIAS DE GOVERNO, como esportes, } \\
\text { educação, saúde, RH etc. }\end{array}$ & NS & NS & NS \\
\hline Var2 & Acesso às empresas públicas: AUTARQUIAS & NS & NS & NS \\
\hline Var3 & $\begin{array}{l}\text { Acesso aos SERVIÇOS ON-LINEDE DOCUMENTAÇÃO para emissão } \\
\text { de guias, certidões, alvarás etc. }\end{array}$ & NS & NS & NS \\
\hline Var4 & Aos FONES e HORÁRIOS de funcionamento dos departamentos & NS & NS & NS \\
\hline Var5 & $\begin{array}{l}\text { Acesso ao PORTAL DA TRANSPARÊNCIA, que mostra as } \\
\text { informações de contratos, finanças, licitações do município etc. }\end{array}$ & NS & NS & NS \\
\hline Var6 & $\begin{array}{l}\text { No acompanhamento das CONTAS PÚBLICAS (orçamentos, } \\
\text { balanços, audiência etc.) }\end{array}$ & NS & NS & NS \\
\hline Var7 & Nas LICITAÇÕES e EDITAIS PÚBLICOS disponíveis & NS & NS & NS \\
\hline Var8 & Nos CONCURSOS e TESTES SELETIVOS disponíveis & NS & NS & NS \\
\hline Var9 & Assunto relativo à oferta de ESTÁGIOS para estudantes & NS & NS \\
\hline Var10 & $\begin{array}{l}\text { No NÚCLEO DE COMUNICAÇÃO, que contém arquivo, notícias, } \\
\text { agendas e informativos da prefeitura }\end{array}$ & NS & NS & NS \\
\hline Var11 & $\begin{array}{l}\text { Acesso à sala do EMPREENDEDOR, que disponibiliza linhas de } \\
\text { créditos às empresas }\end{array}$ & NS & NS & NS \\
\hline
\end{tabular}




\begin{tabular}{|c|l|c|c|c|} 
Var12 & $\begin{array}{l}\text { Acesso ao SISTEMA ELETRÔNICO DE INFORMAÇÕES (SEI) para } \\
\text { verificar a tramitação de documentos, processos administrativos }\end{array}$ & NS & NS & NS \\
\hline Var13 & $\begin{array}{l}\text { Assunto relativo às INFORMAÇÕES GERAIS DA CIDADE, como perfil } \\
\text { da população, fotos, mapas etc. }\end{array}$ & NS & NS & NS \\
\hline Var14 & Para emissão de NOTA FISCAL ELETRÔNICA & NS & NS & NS \\
\hline
\end{tabular}

Fonte: pesquisa (2017) - NS: Não significativo, $\mathrm{S}^{*}$ : significativo a $5 \%(p<0,05)$.

\subsection{Análise do teste não paramétrico: correlação de Spearman}

Por outro lado, mediante o teste de correlação de Spearman, verifica-se, conforme Quadro 7, que há forte correlação positiva (acima de 0,70 ) entre as variáveis em destaque:

$\checkmark \quad \operatorname{Var1}$ (secretarias de governo) com as variáveis: var2 (empresas públicas), var5 (portal da transparência), var10 (núcleo de comunicação) e var13 (informações gerais da cidade).

$\checkmark$ Assim, quando se busca informações sobre assunto relativo às secretarias de governo, como esportes, educação, saúde, recursos humanos, maior é o índice de correlação positiva para busca de informações das empresas públicas, as autarquias $(0,75)$, junto ao portal da transparência, que mostra as informações de contratos, finanças, licitações do município $(0,71)$, junto ao núcleo de comunicação, que contém arquivo, notícias, agendas e informativos da prefeitura $(0,74)$ e assuntos sobre as informações gerais da cidade, como perfil da população, fotos, mapas etc. $(0,73)$.

$\checkmark$ Var2 (empresas públicas) com as variáveis: var4 (fones e horários), var5 (portal da transparência), var 10 (núcleo de comunicação) e var13 (informações gerais da cidade).

$\checkmark$ Quanto ao uso das informações junto às empresas públicas, as autarquias, maior é o índice de correlação positiva para a busca de telefone e horários de funcionamento dos departamentos $(0,72)$, maior acesso ao portal da transparência, que mostra as informações de contratos, finanças, licitações do município $(0,71)$, maior acesso ao núcleo de comunicação, que contém arquivo, notícias, agendas e informativos da prefeitura $(0,71)$, e maior uso das informações gerais da cidade, como perfil da população, fotos e mapas $(0,72)$.

$\checkmark$ Var3 (serviços on-line de documentação) com a variável: var4 (fones e horários).

$\checkmark$ Quanto ao acesso aos serviços online de documentação para emissão de guias, certidões, alvarás etc., maior é o índice de correlação positiva na procura por telefone e horários de funcionamento dos departamentos $(0,74)$.

$\checkmark$ Var4 (fones e horários) com a variável: var13 (informações gerais da cidade).

$\checkmark$ Quanto a busca de telefone e horários de funcionamento dos departamentos, maior é o índice de correlação positiva na procura por informações gerais da cidade, como perfil da população, fotos e mapas $(0,72)$.

$\checkmark$ Var5 (portal da transparência) com as variáveis: var6 (contas públicas) e var10 (núcleo de comunicação).

$\checkmark$ Quanto ao acesso ao portal da transparência, que mostra as informações de contratos, finanças, licitações do município etc., maior é o índice de correlação positiva no acompanhamento das contas públicas em relação a orçamentos, balanços, audiência $(0,82)$ e ao núcleo de comunicação, que contém arquivo, notícias, agendas e informativos da prefeitura $(0,70)$.

$\checkmark \quad$ Var8 (concursos e teste seletivos) com a variável: var9 (vagas de estágios).

$\checkmark$ Quanto ao acompanhamento dos concursos e testes seletivos disponíveis, maior é o índice de correlação positiva no acompanhamento dos assuntos relativos à oferta de estágios para estudantes $(0,74)$.

$\checkmark$ Var10 (núcleo de comunicação) com a variável: var13 (informações gerais da cidade). 
Quanto ao acesso à informação do núcleo de comunicação, que contém arquivo, notícias, agendas e informativos da prefeitura, maior é o índice de correlação positiva sobre assunto relativo às informações gerais da cidade, como perfil da população, fotos e mapas $(0,72)$.

Diante do exposto, rejeita-se a hipótese ( $\mathrm{H} 2$ ) para as variáveis acima mencionadas, ao constatar forte correlação significativa positiva entre as variáveis estudadas (Quadro 7), e por outro lado, deve-se aceitar em parte a hipótese (H2) para as variáveis: var7 (licitações e editais públicos), var 11 (sala do empreendedor), var 12 (sistema eletrônico de informações) e var14 (nota fiscal eletrônica), no qual, embora apresente correlação positiva, enquadrou-se como fraca a moderada correlação pelos coeficientes auferidos.

Quadro 7 - Teste não paramétrico: correlação de Spearman

\begin{tabular}{|c|c|c|c|c|c|c|c|c|c|c|c|c|c|c|}
\hline & Var1 & Var2 & Var3 & Var4 & Var5 & Var6 & Var7 & Var8 & Var9 & Var10 & Var11 & Var12 & Var13 & Var14 \\
\hline Var1 & 1 & & & & & & & & & & & & & \\
\hline Var2 & $* * 0,75$ & 1 & & & & & & & & & & & & \\
\hline Var3 & ${ }^{*} 0,67$ & ${ }^{*} 0,67$ & 1 & & & & & & & & & & & \\
\hline Var4 & ${ }^{*} 0,69$ & ${ }^{* *} 0,72$ & ${ }^{* *} 0,74$ & 1 & & & & & & & & & & \\
\hline Var5 & ${ }^{* *} 0,71$ & ${ }^{* *} 0,71$ & ${ }^{*} 0,63$ & ${ }^{*} 0,57$ & 1 & & & & & & & & & \\
\hline Var6 & ${ }^{*} 0,62$ & ${ }^{*} 0,67$ & ${ }^{*} 0,49$ & ${ }^{*} 0,48$ & ${ }^{*} 0,82$ & 1 & & & & & & & & \\
\hline Var7 & ${ }^{*} 0,60$ & ${ }^{*} 0,60$ & ${ }^{*} 0,65$ & ${ }^{*} 0,63$ & ${ }^{*} 0,67$ & ${ }^{*} 0,65$ & 1 & & & & & & & \\
\hline Var8 & ${ }^{*} 0,61$ & ${ }^{*} 0,60$ & ${ }^{*} 0,62$ & ${ }^{*} 0,65$ & ${ }^{*} 0,64$ & ${ }^{*} 0,56$ & 0,66 & 1 & & & & & & \\
\hline Var9 & ${ }^{*} 0,56$ & ${ }^{*} 0,56$ & ${ }^{*} 0,48$ & ${ }^{*} 0,56$ & ${ }^{*} 0,65$ & ${ }^{*} 0,58$ & ${ }^{*} 0,56$ & ${ }^{* *} 0,74$ & 1 & & & & & \\
\hline $\operatorname{Var} 10$ & $* *_{0}^{*}, 74$ & $*^{* *} 0,71$ & ${ }^{*} 0,56$ & ${ }^{*} 0,67$ & ${ }^{*} 0,70$ & $*{ }^{* *} 0,71$ & ${ }^{*} 0,67$ & ${ }^{*} 0,67$ & ${ }^{*} 0,67$ & 1 & & & & \\
\hline Var11 & ${ }^{*} 0,59$ & 0,57 & ${ }^{*} 0,54$ & ${ }^{*} 0,56$ & ${ }^{*} 0,58$ & ${ }^{*} 0,55$ & ${ }^{*} 0,57$ & ${ }^{*} 0,58$ & ${ }^{*} 0,52$ & ${ }^{*} 0,58$ & 1 & & & \\
\hline $\operatorname{Var} 12$ & ${ }^{*} 0,58$ & 0,69 & ${ }^{*} 0,63$ & ${ }^{*} 0,58$ & ${ }^{*} 0,69$ & ${ }^{*} 0,60$ & ${ }^{*} 0,66$ & ${ }^{*} 0,59$ & ${ }^{*} 0,56$ & ${ }^{*} 0,67$ & $* 0,60$ & 1 & & \\
\hline $\operatorname{Var} 13$ & $*^{* *} 0,76$ & $* * 0,72$ & ${ }^{*} 0,69$ & ${ }^{* *} 0,72$ & ${ }^{*} 0,65$ & ${ }^{*} 0,64$ & ${ }^{*} 0,65$ & ${ }^{*} 0,65$ & ${ }^{*} 0,53$ & ${ }^{* *} 0,72$ & ${ }^{*} 0,58$ & ${ }^{*} 0,68$ & 1 & \\
\hline Var14 & ${ }^{*} 0,50$ & ${ }^{*} 0,49$ & ${ }^{*} 0,63$ & ${ }^{*} 0,45$ & ${ }^{*} 0,52$ & ${ }^{*} 0,50$ & ${ }^{*} 0,55$ & ${ }^{*} 0,34$ & ${ }^{*} 0,33$ & ${ }^{*} 0,42$ & ${ }^{*} 0,50$ & ${ }^{*} 0,53$ & ${ }^{*} 0,52$ & 1 \\
\hline
\end{tabular}

Fonte: pesquisa (2017)

O símbolo * indica que as correlações verificadas apresentam da seguinte forma:

** forte correlação (acima 0,7$)$ e * moderada/fraca correlação (abaixo 0,69)

\section{CONCLUSÃO}

Como conclusão desse estudo, verifica-se que com o aumento das demandas dos cidadãos por melhores serviços é necessário que a gestão municipal ofereça serviços públicos adequados, com informações atualizadas para a tomada de decisão. Nesse sentido, o objetivo da pesquisa, que foi identificar como os cidadãos de uma cidade do Paraná têm acesso às informações geradas pela gestão pública, entende que foi alcançado por meio dos resultados obtidos na análise dos resultados da pesquisa de campo.

Em resumo, considerando as hipóteses postuladas: $\mathrm{H} 1$, que procurou dimensionar se não há diferença significativa quanto ao uso de sistema de informação municipal pelos cidadãos, considerando as variáveis gênero e faixa etária; e $\mathrm{H} 2$, que procura estabelecer se não há forte correlação positiva entre as variáveis pesquisadas, como achados tem-se que:

i) Deve-se aceitar a hipótese $\mathrm{H} 1$, pois os resultados desse bloco de variáveis pesquisadas não apresentam diferenças significativas quanto ao uso de informações dos serviços públicos pelos cidadãos, isto é, não há evidência estatística significativa, considerando os grupos: gênero e faixa etária. 
ii) Deve-se rejeitar a hipótese $\mathrm{H} 2$ para as variáveis, uma vez que ocorre forte correlação positiva:

$\checkmark \quad \operatorname{Var} 1$ (secretarias de governo) com as variáveis: var2 (empresas públicas), var5 (portal da transparência), var10 (núcleo de comunicação) e var1 3 (informações gerais da cidade).

$\checkmark$ Var2 (empresas públicas) com as variáveis: var4 (fones e horários), var5 (portal da transparência), var 10 (núcleo de comunicação) e var13 (informações gerais da cidade).

$\checkmark \operatorname{Var} 3$ (serviços on-line de documentação) com a variável: var4 (fones e horários).

$\checkmark$ Var4 (fones e horários) com a variável: var13 (informações gerais da cidade).

$\checkmark \quad$ Var5 (portal da transparência) com as variáveis: var6 (contas públicas) e var10 (núcleo de comunicação).

$\checkmark \quad$ Var8 (concursos e teste seletivos) com a variável: var9 (vagas de estágios).

$\checkmark$ Var10 (núcleo de comunicação) com a variável: var13 (informações gerais da cidade).

Como contribuição da pesquisa, torna-se importante para:i) melhor planejamento da gestão municipal; ii) apoio à linha de políticas públicas; iii) como fundamentação teórica, propiciando um maior esclarecimento para o grupo de pesquisa em cidades digitais iv) gestão da própria cidade, como indicadores de uso das informações da prefeitura e os assuntos mais utilizados; e v) melhoria da informação e serviços aos cidadãos como apoio à tomada de decisão.

Como limitação da pesquisa destaca-se que os resultados não devem ser generalizados, pois trata-se de uma investigação exploratória mediante uma amostragem não probabilística, o que requer precisar que não expressa necessariamente a mesma realidade de outras cidades de porte semelhante à cidade pesquisada.

Como achados, o estudo aponta um caminho para uma melhor gestão das cidades, com a proposta de qualificar a vida dos cidadãos, uma vez que a conclusão reitera que cerca de $63 \%$ dos respondentes têm 0 hábito de acessar o site/portal da prefeitura para obter algum tipo de informação.

E a conclusão do estudo reitera que entre os destaques nos resultados aparecem o uso dos serviços on-line para busca de documentação, com $56 \%$ de acesso, seguido de acesso às informações gerais da cidade, e aos telefones e horários de funcionamento dos departamentos, ambos com 46,5\%. Por outro lado, informações com baixa utilização são assuntos sobre as ofertas de estágios, com $26 \%$, acompanhamento das contas públicas e acesso à sala do empreendedor, ambos com $29 \%$ de citação, o que sugere pouco interesse desse grupo pesquisado.

\section{REFERÊNCIAS}

BESSELAAR, Peter van Den; BECKERS, Dennis. The Life and Death of the Great Amsterdam Digital City. Digital Cities lii. Information Technologies For Social Capital: Cross-cultural Perspectives, [s.I.], p. 66-96, 2005.

BERHAN, Eshetie; KITAW, Daniel. The role of marketing information systems (mkis) in service quality in ethiopian industries. South African Journal of Industrial Engineering, Bedfordview, v. 23, n. 1, p. 66-76, 05 2012.

CASTRO, Domingos Poubel Auditoria e controle interno na administração pública: evolução do controle interno no Brasil: do Código de Contabilidade de 1922 até a criação da CGU em 2003. São Paulo: Atlas, 2008.

CERVO, Amado Luiz; BERVIAN, Pedro Alcino; SILVA, Roberto da. Metodologia científica. 6. ed. São Paulo, SP: Pearson Prentice Hall, 2007

CHIUSOLI, Cláudio Luiz. Um estudo exploratório sobre tipologias e sistema de informações de marketing. Tese (Doutorado em Administração) - Faculdade de Economia e Administração, Universidade de São Paulo, São Paulo, 2005.

CHIUSOLI, Cláudio Luiz; IKEDA, Ana Akemi. Sistema de informação de marketing (SIM): ferramenta de apoio à gestão empresarial. São Paulo: Atlas, 2010. 
CHIUSOLI, Cláudio Luiz; STEFANO, Sílvio Roberto. Sistema de informação de marketing: importância e uso das informações de marketing na tomada de decisão. Revista Espacios: Revista Arbitrada de Gestion Teconlogica, Caracas, v. 37, n. 11, abr. 2016.

CHOURABI, Hafedh et al. Understanding smart cities: An integrative framework. In: ANNUAL HAWAll INTERNATIONAL CONFERENCE ON SYSTEM SCIENCES, 45., 2012. Proceedings [...]. Washington, DC: IEEE, 2012.p. 2289-2297.

COX, Donald; GOOD, Robert E. How to build a marketing information system. Harvard Business Review, Boston, v. 45, n. 3, p. 145-154, May/June. 1967.

DONG, Bing. Design of Information Management System of Municipal Engineering. Applied Mechanics and Materials, Zurich, v. 608-609, p. 449-453, out. 2014.

FREITAS, Henrique et al O método de pesquisa survey. Revista de administração da USP, RAUSP, São Paulo, v. 35, n. 3, jul./set. 2000.

GIL, Antônio Carlos. Métodos e técnicas de pesquisa social. 6. ed. São Paulo: Atlas, 2008.

GOUNARIS, Spiros P.; PANIGYRAKIS, George G.; CHATZIPANAGIOTOU, Kalliopi C. Measuring the effectiveness of marketing information systems. Marketing Intelligence \& Planning, Bradford, v. 25, n. 6, p. 612-631, 2007.

IBGE - Instituto Brasileiro de Geografia e Estatística. Disponível em: mapasinterativos.ibge.gov.br/censo2010. Acesso em: 15 fev. 2018.

ISMAIL, Shaker Turki. The Role Of Marketing Information System On Decision Making" an Applied Study On Royal Jordanian Air Lines (Rja). International Journal of Business and Social Science, v. 2, n. 3, 2011.

KUBIAK, Bernand F.; KOWALIK, Michal F. Marketing information wystems as a driver of an organization's competitive advantage. Journal of Internet Banking and Commerce, Ottawa, v. 15, n. 3, p. 1-10, 122010.

LEITE, Leornado Oliveira; REZENDE, Denis Alcides. Modelo de gestão municipal baseado na utilização estratégica de recursos da tecnologia da informação para a gestão governamental: formatação do modelo e avaliação em um município. Revista de Administração Pública (Impresso), v. 1, p. 459-493, 2010.

MARCONI, Maria Andrade; LAKATOS, Eva Maria. Fun damentos de metodologia científica. 7. ed. São Paulo: Atlas, 2010.

MARTINS, Gilberto de Andrade. Sobre valide e confiabilidade. Revista Brasileira de Gestão de Negócios, São Paulo, p. 1-12, jan./abr. 2006.

MAYROS, Van; WERNER, D. Michel. Marketing information systems: design and applications for marketers. Radnor: Chilton Book Company, 1982.

MITCHELL, Vincent Wayne; VOLKING, Yin E. Analysing the quality of management information: A suggested framework. Management Decision. v. 31, n. 8, p. London: 1993.

MOTA, Thális Bicalho; OLIVEIRA JÚNIOR, Antônio Márcio Coutinho de; FREITAS, Alan Ferreira de.

Desenvolvimento e uso de um software de gestão sob a ótica das dimensões organizacional, tecnológica e humana em empresas públicas. Navus: Revista de Gestão e Tecnologia, Florianópolis, v. 6, n. 3, p. 70-87, set. 2016.

MURUGADAS, Duwaraka. et al. The Informational World City London. Journal of Documentation, Bradford, v. 71, n. 4, p. 834-864, 2015.

NOVIKOVA, E. N. Design of a marketing information system. Mediterranean Journal of Social Sciences, v. 6 , n. 1 S3, p. 141, 2015. 
O' BRIEN, J. A. Sistema de Informação e as decisões gerenciais na era da internet. 2. ed. São Paulo: Saraiva, 2004

O'BRIEN, Terrence V.; SCHOENBACHLER, Denise D.; GORDON, Geoffrey L. Marketing information systems for consumer products companies: a management overview. Journal of Consumer Marketing, v.12, n. 5, p. 16$36,1995$.

PATASIENE, Irena; PATASIUS, Martin. Digital Dimension in Smart City: Case of Cities of Baltic Countries. Viesoji Politika ir Administravimas, Vilnius, v. 13, n. 3, p. 454-468, 2014.

PEREIRA, Elisabeth Teixeira Almeida; REZENDE, Denis Alcides. Planejamento e gestão estratégica municipal: Estudo de caso do controle interno da prefeitura municipal de Curitiba. Revista Economia \& Gestão, v. 13, p. 52-72, 2013.

PESZKO, Kamila. The consumer as a source of marketing information in the information society. CBU International Conference Proceedings, Prague, v. 3, p. 361-367, 2015.

PORTER, Michael E. Competição: estratégias competitivas essenciais. Rio de Janeiro; Campus, 1999.

RAYMOND, Louis; BRISOUX, Jacques; AZAMI, Abdellah. Marketing information systems practices in small manufacturing firms: Antecedents and consequences. The Journal of Computer Information Systems, Stillwater, v. 41, n. 3, p. 32-41, Spring 2001.

REZENDE, Denis Alcides et al. Information and Information Systems Project for a Strategic Digital City: A Brazilian Case. In: ROCHA, A. et al. (Ed.). Advances In Intelligent Systems And Computing. Berlin: SpringerVerlag, 2013.p. 345-355.

REZENDE, Denis Alcides. Planejamento de estratégias e informações municipais para cida de digital: guia para projetos em prefeituras e organizações públicas. São Paulo: Atlas, 2012.

ROESCH, Ślvia Maria Azevedo. Projeto de estágio e de pesquisa em administração: guia para estágios, trabalhos de conclusão, dissertação e estudos de caso. 3. ed. São Paulo: Atlas, 2005.

ROSA, Marcelo Medeiros da et al. A Lei de Acesso à Informação como instrumento de controle social: diagnóstico dos municípios do sul do Brasil à luz do artigo $8^{\circ}$ da lei 12527/2011. Navus: Revista de Gestão e Tecnologia, Florianópolis, v. 6, n. 1, p. 72-87, mar. 2016.

SALA, Alba María Martínez. Marketing 2.0 aplicado al sector turístico: la función comercial de los sitios webs de las organizaciones de marketing de destinos. Vivat Aca demia, Madrid, v. 21, n. 143, p. 1-23, 1A-22A, jun. 2018.

SALVADOR, Alexandre Borba; IKEDA, Ana Akemi. Gestão de crise de marca: o uso de informações para prevenção, identificação e gestão. Revista brasileira gestão negócio, São Paulo, v. 20, n. 1, p. 7491, Mar. 2018

SIEGEL, Sidney; CASTELLAN, N. John. Estatística Não Paramétrica para as Ciências do Comportamento. São Paulo: Bookman, 2006.

SIMÃO, João Batista. A concepção de um modelo de cidade digital baseado nas necessidades informacionais do cidadão: o caso dos municípios brasileiros de pequeno porte. 2010. Tese (Doutorado em Ciência da Informação) - Faculdade de Ciência da Informação, Universidade de Brasília, Brasília, 2010.

SOUALHIA, Ahlem; MEJBRI, Soumaya. Marketing management des organisations/ Marketing management of organizations. International Journal of Innovation and Applied Studies, Rabat, v. 6, n. 4, p. 1019-1027, 07 2014. 
STOCK, Wolfgang G. Informational cities: Analysis and construction of cities in the knowledge society. Journal of the American Society for Information Science and Technology, v. 62, n. 5, p. 963-986, 2011.

WIERENGA, Berend; OUDE OPHUIS, Peter A. M. Marketing decision support systems: Adoption, use, and satisfaction. International Journal of Research in Marketing, v. 14, n. 3, p. 275-290, 1997. 